\title{
Neo-Fregean Enactivism without RECtifications
}

\section{Márquez C*}

São Paulo University, Brazil

*Corresponding author: Dr. Carlos Márquez, São Paulo University, Rua Engenheiro Sá Rocha, 807, Brasil, Tel: +55 11 951332710; Email: cmmarquezs@usp.br

\section{Research Article}

Volume 4 Issue 2

Received Date: April 22, 2021

Published Date: May 25, 2021

DOI: $10.23880 /$ phij-16000177

\section{Abstract}

The main objective of the present paper is to contrast Hutto and Myin's Radical Enactive, Embodied account of Cognition with some neo-Fregean ideas. By making such contrast my aim is to address the following questions: why and in what sense is it important to recognize that cognition is a normative phenomenon and to attribute contents to minds (even basic minds)? How to develop a non-propositional or non-conceptual account of modes of presentation?

I will argue that the Enactivist Approach is compatible with non-conceptual extensions of the Fregean notion of sense. NeoFregeans impose situated and dynamic conditions on the possibility of having knowledge directed to objects, such that although they endorse a normatively guided conception of contentful states, they are not committed with the postulation of modes of presentations as intermediaries between minds and objects. Consequently, they are not committed with theories of mental representations as symbolic items that mediate that relation.

Keywords: Normativity; Radical Enactive; Embodied account of Cognition neo-Fregeanism; Intentionality; Basic Minds

\section{Introduction}

In this paper I present a gross characterization of what I call neo-Fregean Enactivism -NE-. That characterization is presented taking as background the notion of representation that is the target of Hutto and Myin $(2017,2018)$ Radical Enactive, Embodied account of Cognition -REC- and a general characterization of the Enactive Approach -EA-. REC supports an action or activity-based account of intentionality and cognition, criticizes the Representational Theory of Mind -RTM- and the normative conception of content-involved representations $-N C C$-. $N E$ and $E A$ support also an activitybased account and criticize RTM, but are not against NCC. In contrast to $R E C, N E$ does not support neither the critic to $N C C$ nor their teleosemiotic based account of Ur-intentionality. I present an argument against $R E C^{\prime} s$ teleosemiotic based account of the notion of Ur-intentionality, i.e., the idea according to which a content-purged version of Millikan's teleosemantics is enough to explain the notion of basic intentionality. Finally, I develop a general argument in favor of NCC and present a rough characterization of Cussins's approach to point to a neo-Fregean and non-conceptual content-involving alternative explanation of basic minds.

\section{Radical Enactivism and neo-Fregeanism}

According to Hutto and Myin (2017) -H\&M hereinafter-, the Radical Enactive, Embodied account of Cognition $(R E C)$ is a revolutionary view opposed to the old-school pillars of cognitive science: representationalism and computationalism. As they define it, $R E C$ entails not only to abandon the Representational Theory of Mind $(R T M)^{1}$, "(it also) seeks to leave behind the claim that basic minds are contentful, while nonetheless holding on to the claim that they exhibit a kind of basic intentionality." (Hutto and Myin,

1 As were presented for instance in Fodor J (1975, 1981, 1987, 1994), Stich S, Warfield T (1994), Sterelny, K. (1990). 


\section{Philosophy International Journal}

2017, p.93).

According to them, although every mental phenomenon can be characterized as exhibiting some degree of intentionality, the equation between intentional and contentful states should not be taken for granted (see Schlicht, 2018). Intentionality comes in some varieties. Some mental acts, paradigmatically propositional attitudes, are fully intentional and contentful. Some other, the kind of activities exhibited by basic minds, are Ur-intentional and propositionally contentless.

Digging deeper, $R E C$ is a position not merely against the ascription of propositional or conceptual contents to basic minds ${ }^{2}$. It entails also to abandon non-truth-conditional specifications of contents in terms of correct, satisfaction, appropriate or skillful conditions. $H \& M$ recognize that some philosophers have given up the equation between contentful and propositional or truth-conditional states, without giving up the equation between intentionality and, as they call it, semantic normativity. Crane (2009) and Gunther (2003, pp.5-6), for instance, argue that ascriptions of contents based on correctness conditions are still necessary to explain intentionality, although not necessarily ascriptions of contents specified in terms of truth-conditions. By contrast REC is committed to the following thesis: semantic normativity is neither the mark of primitive intentionality nor the mark of primitive cognition ${ }^{3}$ (see Hutto and Myin, 2017, p.101).

$R E C$ is also committed to the denial of any extension of the Fregean notion of content with its paradigmatic distinction between sense and reference. It denies that an appropriate way to provide an account of basic cognition is to ascribe (a different variety of) modes of presentations determined in

2 Hereinafter I will assume that the discussion is about the attribution of intentionality to basic minds. I am aware that H\&M admit that non-basic forms of cognition involve ascriptions of thoughts and mastering linguistic or social conventions, but my objective is to discuss about the ascription of contents and normative conditions at the level of basic cognition. More on my use of the expression 'normative conditions' latter.

3 REC urges us to abandon also the "computational view of the mind, which downplays the importance of the physical body" (Thompson E, 2018) For the porpoises of the present paper, I will focus only in the first traditional tenet (representationalism), not in the second one (computationalism). Since, although non-entirely uncontroversial, it can be argued that the second tenet is constrained by the first one. As Cussins (2012, p.9) puts it: "Computational explanations depend not only on the nature of representational vehicles, but also on their contents. So if it turns out that there is more than one kind of content, then that result affects our understanding of the space of possible computation". I am not thinking as a classic computationalist like Fodor that all forms of computation entail a type of symbolic representation, but that different -maybe sub-symbolicnotions of content can broaden our understanding of different notions of computation -not necessarily disembodied or unsituated- (see Cussins, 1990). virtue of (some different varieties of) normative conditions (See Hutto and Myin, 2017, p.103).

When I say -simpliciter- that $R E C$ is a position against the need to introduce normative conditions, I mean more exactly the following: although $H \& M$, strictly speaking, do not deny that basic forms of intentionality involve a kind of normativity, they claim that those forms of intentionality do not involve or require explanations that resort on notions of being correct or being wrong about worldly features. They distinguish between semantic and biological normativity ${ }^{4}$ and claim that basic intentionality involves the latter but not the first. The point of their distinction is not merely to argue that there is no need for a basic organism to represent the correctness conditions in virtue of which his states are directed or responsive to worldly offerings, but also to conclude that correctness conditions are not needed at all to explain basic intentionality and basic cognition.

Notions of adaptive and dynamical world-targeting responsiveness could be needed in order to distinguish between circumstances in which organism's interactions with their environment function properly (or under proper conditions) and circumstances in which those interactions go awry, fail or malfunction according to the phylogenetic history, but there is no need to introduce any notion of answerability or being committed to the world being in some way or getting things right or wrong. As they say:

A more radical view is possible; we can surrender the idea that basic forms of intentionality need involve correctness or satisfaction conditions of any kind ... since most analytic philosophers assume that content entails correctness conditions, to introduce talk of intentional content at this crucial juncture is likely to breed only confusion. Hence REC recommends the keeping to the vocabulary of contentless intentionality rather than nonrepresentational intentional content (Hutto and Myin, 2017, pp.101-102).

It is clear that their specific target is this normative and intensional notion of representation. The notion of mental representations as contentful states or states with intensional properties, i.e., states that present their worldly targets as being a certain way. A notion useful to explain how it is possible for an organism to be able to take or get things right or wrong (see Hutto and Myin, 2018, p. 191). That normative conception of contents is not necessarily tantamount neither to the biologically normative notion of being reactive to targets relative to etiological proper conditions nor to the semantic notion of being able to get

4 I will talk in more detail about this distinction later. 


\section{Philosophy International Journal}

things true or false ${ }^{5}$. Hereinafter I will call it the Normative Conception of Contentful states or NCC for ease of reference. $H \& M$ characterization of Radical Enactivism entails to deny NCC, namely: attributing intentionality to basic minds does not involve ascribing them states in virtue of which their worldly targets are presented as being a certain way so that they are able to get things right or wrong.

The classical enactive approach ${ }^{6}$ is not necessarily committed to the denial of NCC. As Thompson (2018) points out "neither (Merleau-Ponty nor Freeman) would say that basic cognition is contentless ... Nor would they say that the intentional content has no satisfaction conditions, in the sense that it is not subject to norms". Thompson also points out that the enactive approach is not against the ascription of modes of presentation to basic minds:

When Hutto and Myin claim that "ur-intentionality" directly targets its object, it may be that they mean to deny the model of intentionality in which it consists of an object, an act or attitude, and a mode of presentation. But although they argue that basic cognition is not representational, they do not provide any argument to show that it does not involve modes of presentation. They mention the idea ... that "there is intentional content to which Frege's sense-reference distinction does not apply" (p. 103). They go on to say, "to let go of the idea of a sense-reference distinction, while retaining the idea of some kind of intentional directedness ... is actually to go the REC way" (p. 103). But Frege's sense-reference distinction concerns language and linguistic thought. We are still left with the question of whether basic cognition, which is nonlinguistic, involves nonrepresentational modes of presentation. Phenomenologists maintain that it does. (Thompson, 2018)

It seems to me that not only phenomenologists have something to say about the possibility of broadening the notion of modes of presentation beyond linguistic cases. Although it is right to point out that Frege's enquiries were about the structure of thoughts and the relations between them, it does not seem accurate to characterize his observations as being concerned exclusively with linguistic phenomena. Anyway, leaving behind the interpretation of Frege's philosophy, neo-Fregean conceptions of meaning

5 For more about the distinction and some reasons to claim that biological normativity is not only enough to sustain the normativity of truth but also is not enough to sustain the notion of objectivity intrinsic in rule-following relations -the possibility of being able to get things right or wrong about how things are- see Haugeland (1998).

6 As presented for instance in the autopoeitic version of Varela, et al. (1991), Froese and Di Paolo (2011), Di Paolo, et al. (2017), Thompson $(2007,2018)$ or in the sensory-motor version of Nöe $(2004,2012)$.
-Evans, 1982, 1985; McDowell, 1996, 1998, 2003, 2013; Cussins 1992, 1993, 1999, 2002, 2012; Campbell, 2002are for sure not merely concerned with explaining the abilities required to learn and understand a language. Their considerations are broadly directed to address questions about the conditions of possibility of having thoughts about objects, even when thoughts are not dressed in their linguistic clothes. But also and more fundamentally, they address general questions about the conditions of possibility of having cognitive states objectively directed to worldly features, i.e., about the conditions of possibility of having objective experiences ${ }^{7}$. An explanation about how it is possible to have states directed to a reality to be cognized. That reality can be independent of the subject's history and his dispositional fabric of states, even if it is presented as a structure of objects, properties and relations or as featureplacing structures (Strawson, 1997) that guide primitive forms of activity. In any case the important point is to enquire about the conditions under which something is given in an organism's experience to be cognized. Their point is about how features are presented or given in experience and how can be objectively presented. How can objects or features be given in experience as things that are independent of the subject and its states (be it a mammal or an anaerobic bacteria); and, if not objectively, how are features be plainly presented to an organism ${ }^{8}$ ?

It maybe that there is a level of cognition and intentionality at which features are not objectively presented as independent from the cognitive agent and its states or a level at which features are not only not objectively presented but not presented at all. In any case, to claim that basic minds can cognize something without something to be presented in his experience to be cognized is at least a proposal in need of a substantive justification. That position at least goes against the phenomenological reception of Brentano's notion of

7 To illustrate the point consider the following passage from McDowell : "What is needed is an understanding of how content, explicitly conceived as inaccessible except from inside, can be comprehended as a precipitate of simpler modes of activity and awareness than those in which it figures" (1998, pp. 104-105).

8 It is worth noticing that being committed to that idea that something should be given in the organisms experience in order to be cognized does not imply necessarily to commit oneself with the idea that it should be conceptually presented. Campbell (2002), for instance, argues in favor of a Relational (unmediated by any conceptual content) View of Experience. "On the Relational View, experience of objects is a more primitive state that thought about objects, which nonetheless reaches all the way to the objects themselves. In particular, experience of an object is what explain your ability to grasp a demonstrative term referring to the object ... the way in which you are given an object has to be what causes and justifies the pattern of use that you make of the demonstrative" (Campbell, 2002, p.122-126). As I will explain latter, Cussins argues in favor of a non-conceptual form to be presented in experience that steers between McDowell's conceptualism and Campbell's Relational View. 


\section{Philosophy International Journal}

intentionality. As Gallagher and Zahavi tell us :

The dominant tendency in phenomenology has been to question the partition and to argue that the problems of experience and intentionality are intimately connected... according to phenomenologists it is not possible to investigate intentionality properly without taking experience, the first-person perspective, first-person meaning, etc., into account. And vice versa, it is not possible to understand the nature of subjectivity and experience if we ignore intentionality. To think otherwise is to run the risk of reinstating a Cartesian subject-world dualism that ignores everything captured by the phrase being-in-the- world (Gallagher and Zahavi, 2012, p.125).

When $H \& M$ emphasize the idea according to which the content-involving account of cognition is related with the normative conception of contents, they claim that $R E C$ is not committed to the denial of the ascription of phenomenal contents.

The notion of content that REC denies ... does not automatically include what is sometimes called phenomenal content. It cannot be taken for granted that to enjoy an experience with a certain phenomenal character is to be in a state of mind with representational content. A great deal of argument would be needed in order to establish such a reduction or identity (Hutto and Myin, 2017, p. 11).

$H \& M$ recognize that the notion of correctness conditions can be stretched enough to cover cases of non-propositional or non-truth-conditional contents (see Hutto and Myin, 2017, pp. 10-11). They call the previous position: the Content Involving account of Cognition -CIC-. CIC claims that for an agent to cognize something it is necessary to ascribe states that present the world as being a certain way, the determination of such contents is fundamentally dependent on the determination of the conditions under which such states get things right or wrong. According to H\&M one can deny CIC without abandoning ascriptions of phenomenal contents. Therefore, $H \& M$ are clamming that there is a basic level of intentionality at which features are objectively or at least plainly presented and that for things to be presented in the organism's experience there is no need to situate those given things under the normative framework of being able to get things right or wrong. In other words, there is a level at which phenomenal contents can be ascribed, without the need to situate the ascription of phenomenal contents under a space of correctness conditions. As they say:

9 See Gallagher and Zahavi, 2012, pp. 123-146
The foregoing observations reveal that some philosophers use the word con- tent so liberally that it just picks out the object of experience, perception, or thought, whereas others use the notion in a restrictive sense that entails the existence of some kind of satisfaction conditions. These two uses must not be conflated ... a great deal of argument would be needed to establish that all acts of world-engaging experience, perceiving, or thinking involve contents with conditions of satisfaction (Hutto and Myin, 2017, p. 12).

I take neo-Fregeans as arguing that ascriptions of contents are fundamentally related to explanations of how an organism can get things right or wrong. They have as a common background Frege's anti-psychologism and a common critic to the notion of the (bare) Given. Certainly it is a great deal to provide an argument that constitutively relates phenomenal contents with correctness conditions. Such an argument would require dealing in detail with some of the more subtle philosophy: Frege's $(1948,1956)$ critic to the notion of psychological ideas unframed on the logical and normative notion of being directed to the truth, Dummett's (1991) critic to notion of bare referents and McDowell's $(1996,2013)$ argument against the Given. But it is not necessary to enter in those deep waters. The following general point is enough to argue against $H \& M$ : there is no need to reduce phenomenal contents to semantic contents to state that the question about how it is possible for things to be given in an organism's experience is fundamentally and intrinsically related to the question about how it is possible to get things right and wrong. There are not bare presences neither at the level of thought nor at the level of experience. That is a point that both phenomenologist and neo-Fregeans would agree on. I will try to stay at least the superficial lines of an argument in favor of this point in the third section.

Neo-Fregeans are committed to NCC. They can also be understood as being committed to some tenets of the Enactive Approach. According to Thompson:

The enactive approach is a cognitive science research program based on two interconnected pillars (see Varela et al. 1991; Thompson 2007; Di Paolo et al. 2017). One pillar is the rejection of the representational theory of mind, the emphasis on the dynamics of agent-environment sensorimotor coupling, and the thesis that embodied interaction is constitutive of cognition. The other pillar is the concept of biological autonomy. The basic idea is that living beings generate and maintain themselves. Stated more abstractly, an autonomous system is a self-generating and self-sustaining system. The theory of autonomous systems takes living systems as the paradigm and focuses on explaining the 


\section{Philosophy International Journal}

emergence and constitution of individuality, agency, and functional and behavioral norms. The theory of agent-environment coupling focuses on explaining cognition. For an account to be 'enactive' in the full and precise sense of the term, it must include both theoretical projects (Thompson, 2018).

Evans, McDowell, Campbell and Cussins endorse insights according to which embodied, active, dynamical, situated and autonomous interactions are constitutive of intentionality, cognition and meaning. In contrast with $R E C$, they do not claim that it is necessary to abandon the NCC characterization of representations, only $R T M^{10}$. In contrast with $R E C$ and the Enactivist Approach they do not reduce the theory of autonomous and self-sustaining NCC systems to a purely biological characterization. Bypassing their substantial differences, the following common view can be derived: an account of the dynamic and situated conditions required for the world to be presented in experience is neither committed with the abandonment of NCC nor committed with endorsing a purely evolutionary account of primitive intentionality ${ }^{11}$. It could be the case that after all no neoFregean feels comfortable with the notion of representation. Campbell is an example. But contrary to REC it seems that no neo-Fregean is disposed to abandon NCC. They do not seem to think that NCC is incompatible with claiming that objects (or features) are directly given in experience. I will call that view Neo-Fregean Enactivism ( $N E$ for short).

Since NCC and CIC consists in claiming that ascriptions of (different varieties of) contents are intrinsically related to attributions of (different varieties of) correctness conditions it would seem that there is no any difference between both views. But there is a crucial difference: whereas H\&M's Content Involving account of Cognition -CIC- imply that content ascriptions are incompatible with the postulation of directly given objects (or features), neo-Fregean's Normative Conception of Contents -NCC- does not imply that content ascriptions exclude the possibility of something being directly given in experience (or thought).

For $H \& M$ being Radical about Enactivism means to be committed with the denial of NCC, i.e., the denial of the answerable dimension of mind and the ascription of modes in which the world can be rightly or wrongly presented. They do not seem to contemplate the view that it is

10 For a direct and unmediated representationalist approach to body knowledge see Cussins (2012).

11 Luntley (1996), McDowell (2005) provide interesting and brief introductions to the neo-Fregean dynamic and situated conception of Fregean senses. To the extension of the point relative to the notion of experience see McDowell, 1996, 1998, 2003, 2013; Cussins 1992, 1993, 1999, 2002, 2012; Campbell, 2002; Evans 1982, 1985 and Travis, 2017 possible to deny the representational conception of states as symbolic intermediaries between mind and world and endorse a situated, dynamic, content-based and normatively framed conception of how things are given in basic mind's experiences. Following NE, I will try to argue that in order for cognitions (even basic cognitions) to be answerable to worldly features those cognitions should be presented in some way to the organism and that states that are not answerable to a way in which the environment is are not cognitive states (although they could be characterized as reactive behaviors).

\section{Contentless Intentionality}

According to $\mathrm{H} \& \mathrm{M}$, basic minds exhibit a kind of primitive intentionality that is not exhaustively explained by behaviorist accounts and is not NCC. Their main difficulty is precisely to steer between the behaviorist conception and NCC. That is, to provide an account of world-relating or world-directed mental attitudes in terms of forms of activity not normatively guided, avoiding at the same time merely reactive characterizations. By merely reactive I mean that basic minds are not reactive agents: agents whose interactions with the environment are exhaustively explained in terms of causal or dispositional chains of stimuli and response. By not normatively guided, as I explained in the previous section, I mean not only that basic minds do not represent correctness conditions, but also that there is no need to ascribe to them any -intrinsic- sensitivity to getting things wrong or right or any -intrinsic- answerability to how things are. Discussing Neander (2017) arguments in favor of the postulation of intensional contents for the visual system, $H \& M$ claim the following:

It may be that the content ascriptions to states of perceptual systems are assumed by those who make them to describe the intensional contents of such systems. Yet even if that is the case, does it get us any closer to establishing that perceptual systems, in fact, operate with intensional representations? The illustrative example of AH's deficit shows that a state of her visual system can be given various intensional descriptions ... Yet that, in itself, does not secure what defenders of RTM, canonically construed, need to establish - namely, that we have good reason to think the states of perceptual systems themselves exhibit intensionality ... It would be a blatant non-sequitur to move from the fact that the visual system can be described, intensionally, as representing a target in a certain way to the conclusion that the visual system represents a target in a certain intensional way (Hutto and Myin, 2018, p. 194).

This movement suggests that, for them, someone who defends the notion of normative guidance or -intrinsic- 


\section{Philosophy International Journal}

sensitivity to getting things wrong or right is committed to the postulation of internal representations or to the ascription of intensions to systems from the possibility of intensional descriptions of the system. Since neo-Fregeans endorse Frege's anti-psychologism it does not seem accurate to ascribe to them an internalist view about cognition. When they speak about something being presented in experience they are not thinking that from the possibility of intensional description of a system it follows that the system has intensional states internally individuated. I will use the vocabulary of "intrinsic sensitivity to the surroundings" as a way to mark that the notion of content is structurally linked to the notion of being answerable to the world as the source of normative authority (see McDowell, 1996, pp. xii-xiii).

$H \& M$ believe that they can provide a non-normative (in the sense specified previously) and non-reactive account of mental activity by removing the vocabulary of representations, contents and correctness-conditions from a collection of explanations available nowadays. To name a few: Howy (2013) and Clark (2016) Predictive Processing account of Cognition; Varela, Thompson and Rosch (1991), Thompson (2007), and Froese and Di Paolo (2011) Enactive Approach $^{12}$; Millikan (2005) Teleosemantics; (4) Chemero (2011, 2013) Ecological Dynamics; Gibson (1979) direct account of perception in terms of affordances; (5) Dreyfus (2002, 2013) characterization of absorbed skillful copying; Clark and Chalmers (1998) extended mind hypothesis.

Given this mosaic of explanations it is difficult to name exactly which ones are precisely the elements that allow $H \& M$ to steer between NCC and the behaviorist conception of mind. Some resources included in the list are: embodied anticipative capacities that conform to Bayesian predictions; "target-focused, biologically based normativity" (Hutto and Myin, 2017, p.104); absorbed coping spontaneous responsiveness; affordances and relational cognition; biologically based explanations of autonomy, spontaneity and agency; attributions of practical knowledge or "knowhow learned through unprincipled interaction" (Cappuccio

12 Labeled by Hutto and Myin Autopoietic Adaptative Enactivism (AAE). Miss-labeled according to Thompson (2018): "Hutto and Myin use the term "autopoietic-adaptive enactivism" to refer to the enactive approach. The word is a misnomer for several reasons. First, no exponent of the enactive approach uses it. Second, "autopoiesis" refers to the kind of autonomy found at the level of the single biological cell. The theory of autopoiesis provides a paradigm for conceptualizing and modeling the autonomy of living beings at the level of single-cell metabolism. "Autonomy", however, is the generic concept. It is the conceptual tool directly relevant to explaining individuality and agency. Third, "adaptive" stands for "adaptivity", which refers to the capacity of an autonomous system to regulate itself in relation to conditions registered as viable versus unviable, or improving versus deteriorating. All living organisms are autonomous and adaptive ... In addition, central to the enactive approach is a critique and critical rejection of the adaptationist and selectionist perspective in biology that underwrites teleosemantics and Hutto and Myin's teleosemiotics". and Froese, 2014, p. 4). Any of those notions or an appropriate combination of them will do the work to provide a not normatively guided characterization of cognition (in the sense previously specified). I will focus on the postulation of "target-focused, biologically based normativity" because $H \& M$ claim that a reduced -non-semantic- version of Millikan's proposal is enough to characterize the notion of Ur-intentionality in naturalistic terms (see Hutto and Myin, 2017, pp. 104-114).

The story roughly goes according the following lines: basic minds are structured by systems that have states that covary with states of the environment. Some systems are naturally selected because they are adaptively valuable for the cognitive agent. Some other are not evolutionary privileged because they do not have an adaptive impact. A basic mind is directed to the environment because its biological proper function is to produce some states that covary with some states of the environment and not with others. Described in those terms, basic minds are no more than reactive systems selected in virtue of their adaptability. Teleosemantics, however, is a more sophisticated view. It gives a predominant role to consumer devices as interpreters performing proper functions under normal conditions specified by biological norms. Correspondingly, intentional directedness is not reduced to casual and dispositional relations. Proper functions are not specified by determining what the producer/consumer devices actually do, nor what they are disposed to do. Proper functions are determined by what the system is supposed to do according to biological norms in virtue of which normal conditions of covariance are established ${ }^{13}$. Conditions in virtue of which performances of the organism or of its organismic systems are properly enabled. Even if producer/consumer devices are not functioning -if they do not perform or are not disposed to perform its statistically regular function- they still have a proper function that they should -or are supposed toperform. When H\&M endorse teleosemantics they are buying the idea according to which basic minds are not merely reactive minds because teleosemantic accounts in terms of proper functions posit a biologically based normativity that goes beyond causal and dispositional reductions.

One argument against teleosemantics is that

13 Normal in the sense of appropriate, not in the sense of statistically regular. As Millikan (1994, pp. 246) tell us: "My term "normal" should be read normatively, historically, and relative to specific function. In the first stance, "normal" applies to explanations. A "normal explanation" explains the performance of a particular function, telling how it was (typically) historically performed on those (perhaps rare) occasions when it was properly performed. Normal explanations do not tell, say, why it has been common for a function to be performed; they are not statistical explanations. They cover only past times of actual performance, showing how these performance were entailed by natural law, given certain conditions, coupled with dispositions and the relevant functional devices" 


\section{Philosophy International Journal}

teleosemantics does not provide an account of truthconditional semantic contents (see Putnam 1992 and Haugeland 1998). That's the main reason why $H \& M$ avoid Millikan's target -namely, to provide an account of mental representation. Since they propose that there could be a basic level of intentionality at which semantic normativity is not operative, they assume that any critic to Millikan's proposal can be avoided by purging Millikan's account of any pretense to explain the notion of representational or intensional states. Consequently, they endorse Millikan's theoretical apparatus and claim that it can be used to explain a more primitive relation of contentless directionality.

Let us review this move for a moment: A part of Putnam's (1992) critic to teleosemantics consists in arguing that it does not satisfy Fodor's (1987, p.126) requirement of providing an account of semantic and intentional notions in "nonintentional, non-semantical, non-teleological, and in general, non-question-begging vocabulary". One way ${ }^{14}$ to appreciate this point is to consider the following dilemma: teleosemantics relays on evolutionary explanations to determine what a device is supposed to do. Either the explanation determines what the device is supposed to do taking into account strictly speaking the historical record of what it $\mathrm{did}^{15}$, or the explanation is permeated by counterfactual evaluations. The first option is not sufficient to sustain the notion of biological normativity. The adaptive record does not determine by itself what the device should or is supposed to do. The second option is sufficient, but it involves setting the phylogenetic record under the frame of a biological explanation. Given that biological explanations are permeated by counterfactual evaluation and require demarcation criteria to distinguish between relevant and irrelevant situations of evaluation, the notion of biological normativity is not entirely dispensed of the vocabulary of correctness conditions. Biological norms rule out situations sufficiently odd to be considered for counterfactual evaluation. Either those norms are settled by considering how in previous cases the organisms survived in virtue of being adapted to the environment, but then they tell us only what has happened and not what should happen, or they are subject to counterfactual evaluations and are framed in a biological explanation, but then they involve the introduction of counterfactual evaluations and correctness conditions (see Putnam, 1992, p.26).

$H \& M$ do admit that teleosemantics is not enough to

\section{Another way is presented in (Haugeland 1998 pp. 308-310).}

15 To ascribe a proper function to a device consists more or less in the following: if in those occasions when the device performed $X$, the performance of $\mathrm{X}$ increased the rate of adaptation so that the device was selected because it performed $X$, then the proper function of the device is to perform X. The appeal to natural selection involves not only that the performance of X had an effect on the organism's survival but also that it will have the same effect in the future. sustain the notion of semantic normativity. They assume that displacing the target of teleosemantics is enough to block Putnam's argument. If teleosemantics does not succeed in naturalizing intentionality because it does not satisfy Fodor's requirement (to try to explain semantic and fully intentional notions in terms of non-semantic and non-intentional ones), it is better to leave aside Fodor's requirement. Their proposal is to appeal to a usual strategy of divide and conquer: On the one hand, to explain Ur-intentionality resorting on the non-semantic and non-intentional notion of "target-focused, biologically based normativity". On the other hand, to explain semantic and fully intentional notions in content-involving terms (see Hutto and Myin 2017, p. 43; 2018, p. 196)

As Fodor would say "Darwin doesn't care how you describe the intentional object of fly snaps ... Darwin cares how many flies you eat, but not what description you eat them under" (Fodor 1990, p. 73). But they claim at the same time that it is not necessary to reduce the scope of biological explanations to the determination of intensional contents. We can perfectly assume that biological normative notions are not enough to sustain cognitive levels of being true or false about something, without denying that those notions are enough to explain less intellectual levels. As Putnam (1992, p.31) would say, "Evolution didn't "design" dogs' "ideas" to be true or false, they designed them to be successful or unsuccessful". Biological normative notions are not enough to determine representations of the world as being in a certain way in order for the organism to be able to get things right. But, $H \& M$ tell us, it does not matter at all, since the target is to explain non-semantic and nonfully intentional properties. They admit that biological explanations do not determine intensional contents. But, the claim is: determining extensionally what the device is supposed to do is enough to explain that it is directed at something.

Relocating the target of the account from semantic and fully intentional properties to primitive intentionality, however, does not block the point according to which the normative character of biological explanations is dependent on notions of correction. It can be replied that individual organisms do not, and do not need to, represent biological norms and correctness conditions. They only need to follow or to behave according to those norms. An organism can go wrong in its interactions with the environment (can fail or malfunction), without assuming that it has represented the environment wrongly. Granted. But there is no reason why Putnam's conclusion can not be extended to ateleosemantics's content-purged version. As Putnam tell us:

The most telling argument against the idea that evolution explains intentionality is that the whole reference to evolution play no role in the "explanation" just sketched. What seems to give us 


\section{Philosophy International Journal}

an account is not the theory of evolution, but the use of counterfactuals and the appeal to considerations of selective reproduction of certain functions (Putnam, 1992, p.33).

H\&Madmit that teleosemantics could solve the problem of semantic indeterminacy (to provide elements to individuate fine-grained contents using exclusively resources from evolutionary biology), only at the expend to recognize that what makes the work for determining different fine-grained contents are different counterfactual analyses (see Hutto and Myin, 2018, p. 196). Although the use of counterfactuals determine uniquely fine-grained intensional contents ${ }^{16}$, that use situates biological explanations under a frame of correctness conditions ${ }^{17}$. It is true that an organism does not need to have an internal representation of the correctness conditions in virtue of which a biological norm determines what it would be for it to be biologically successful. But, at least the following minimal concession should be made: it is not plainly true that correctness conditions are not needed at all in this kind of explanation. Even changing teleosemantics's target, $H \& M$ should admit that correctness conditions are involved at some level of the explanation. Their point, however, they insists, is that organisms do not need to have fine-grained intensional representations of its targets -nor to be sensitive to the correctness conditions- to be directed to -or responsive- to their targets. To explain basic intentional states it is enough to determine extensionally their targets.

\section{Content-involving Intentionality}

How is it possible for thoughts to be directed at how things are? Thinking that $a$ is $F$ is detachable from $a$ being $F$. By detachable I do not mean that mental states are always detached from its surroundings or that there is at least one occasion in which a mental state is detached from its surroundings. What I mean is the following: even if in all of its interactions to its surroundings when a cognitive agent has an attitude directed to $X$, the environment is $X$; there could be (counterfactually) the case that the cognitive agent has the attitude directed to $X$ and the environment not be $X$. Opacity is the mark of the mental, at least of propositional attitudes ${ }^{18}$. Within the scope of this consideration it is easier to recognize the normative-guiding character of intentionality and the requirement to postulate modes of presentations. Thoughts are not reduced to what is the case, they are corrected by -or answerable to- what is the case. Consequently, it seems a better option to specify the structure of thoughts in

16 That is the alternative pursue by Fodor (1990).

17 That is essentially Putnam (1992) critical assessment of Fodor's view.

18 For an argument in favor of this thesis see Simons P (1995) I thank Professor Ludovic Soutif for pointing to me this paper. intensional and not merely in extensional terms ${ }^{19}$.

There is a traditional reading of Frege according to which understanding a sentence consists in knowing the truthconditions of the thought expressed in the used sentence. That however is not exactly equivalent to Dummett's and McDowell's reading. They point out that Frege speaks of judgments as transitions from thoughts to the truth. Reference and truth are not properties of senses and thoughts, but aims at which senses and thoughts are directed (See Frege, 1948, 1956, McDowell, and Travis, 2017). Semantic theories established purely in terms of truth-conditions do not capture this requirement of normative-guidance. Enquiring for the link between thought and truth requires providing a theory of what is to advance from thoughts to the truth, and not to state whichever coextensive set of truth-conditions. The development of a semantic theory reduced to ascriptions of semantic values and truth-conditions does not capture the difference between how a speaker is committed to a referential structure. A theory of what it is for a thinker to be committed to certain structure of the truth and not to other is needed to supplement or frame the semantic theory. For McDowell, that bill is paid by considering that specifications of truth-conditions are intrinsically related to the attributions of attitudes in terms of which linguistic behaviors of speakers in a community become intelligible (McDowell, 1998). In other words, the bill is paid by revealing the codependence between the theory of sense, the theory of reference and the theory of force. For Dummett, that bill is paid if there is a (provisory) priority of the force theory over the theory of reference ${ }^{20}$. The point here is that both philosophers argue that contents are not determined purely in terms of bare extensions. The ascription of senses is determined by setting truth-conditions relative to specific epistemic commitments of language users.

Fregean cases are only instances of that general issue. Frege introduced the notion of sense to explain how it is possible to preserve speakers' rationality in cases where about the same thing it is possible to believe and not to believe that it satisfies the same property. If "Phosphorus" and "Hesperus" are co-referential terms, "Hesperus is Hesperus" and "Hesperus is Phosphorus" are true sentences. If meanings are reduced to extensions, then to understand "Hesperus is Phosphorus" implies to know that "Hesperus is Phosphorus" is true. The main problem here is not to explain why a sentence can have the same semantic value

19 Another option is to complete the extensional determination of propositional contents with a story about cognitive attitudes (as some neoRussellians do). In any case a normative framework should be provided.

20 It is worth noticing that Dummett is ambivalent. Sometimes he seems to maintain a priority of the theory of force over the theory of reference and other times he seems to argue in favor of a codependency. 


\section{Philosophy International Journal}

and different cognitive values, but to explain how someone can understand a sentence without knowing its truth-value. A Fregean speaker grasps a thought, if he knows how to advance from the thought to a truth-value. The postulation of that normative relation between thoughts and truth gives us the general frame to explain why the speaker by grasping a thought and knowing its truth-conditions does not know its truth-value. To know the truth-value requires constitutively the possibility of sustaining a commitment assessable to how things are or to what is the truth in an occasion.

Travis establishes the point in the following terms:

If an argument were needed for Sinn, it would be something on these lines. A thought is, by fiat, that by which truth can come into question at all ... A thought is thus that which makes truth turn in some determinate way on how things are. It is what performs a certain task, precisely that which does given work. For Frege, whole thoughts come first; proper thought-elements are to be carved out of them, are attained by decomposing a thought. In the case of a singular thought, one thing to be arrived at by such decomposition is an element which makes the thought about some object in particular: for it to be that thought is for truth to turn on that object. Such a thought element makes truth turn (in part) in a certain way on how things are. And now the point is just: no object makes the truth of any thought turn on it (or on anything else) (Travis, 2017, p.9)

I think that the main moral from the previous stories is that the relation between truth and meaning is not reduced to "scientific systematization of regularities in a complex phenomenon" (Dummett, 1987, p. 260). A theory of judgment is neither a psychological nor a behavioral theory nor a theory of semantic regularities. Of course, judging, thinking and inferring are processes that satisfy psychological, behavioral and semantic regularities. But, constitutively they are rational activities governed by commitments ${ }^{21}$ and are not reduced to any set of regularizations or conditions.

A way to reveal that the notion of intentionality is constitutively linked to NCC is to frame the previous considerations under the scope of Wittgenstein's (2009) rule-following argument. As Brandom (1998) states it: rules are not reduced to regularities. Brandom's reading of the rule-following argument entails postulating a pragmatic level of linguistic practices that serves as a basis for upper

21 See Haugeland (1998) for an attempt to define the notion of commitment and a distinction between four kinds of normative commitments related to objective experience. I do not think it is necessary to characterize the notion of commitment to state the general point. That characterization would take a lot of ink and involves a lot of subtle philosophy that goes beyond my present intentions. levels of interpretation where the normative notion of correctness-conditions applies. McDowell (2002b) rejects that view of a basic level of (pragmatic) practices that sustain higher levels of (semantic) interpretation. According to him an understanding of an expression is by itself a practice. The conception of meaning and mind as normatively guided goes all the way out. If the conception of meanings as normatively guided goes all the way out ${ }^{22}$, it is simply not possible to provide a theory of content as from outside, the only possible way is to provide an account from within as achievements from simpler forms of activity.

Although it is easily appreciated for the case of propositional attitudes, the conception of meaning and mind as normatively guided does not depend on the conception of minds as related with propositional or conceptual contents. If the ways to react of basic minds were always in tandem with their possibilities of action, they wouldn't be more than reactive agents. Similar to heat-seeking missiles that change irremediable their trajectory according to changes in their targets. If basic minds were perfectly guided and infallible, and opacity were not the mark of the mental, they would be only reactive systems. It should be possible for minds -even basic minds- to be able to react in some ways that do not accord to what the environment offers. In order to cognize an environment, a mind -even a basic mind- should be minimally guided and responsive to it.

At this point $H \& M$ would probably point to us that some pragmatic notions that we leaved behind are also present in their explanation. Basic organisms does not merely react to their environment, they cope or are unprincipled guided by their biological needs. But see now what is happening: if the practical responsiveness to worldly offerings that is at stake is not to be reduced to fits or misfits with the environment offerings, that practical responsiveness should obey to ways to be committed to such offerings. Having practical abilities involves constitutively to be normatively guided. Postulations of anticipative capacities, target directed capacities, spontaneous responsiveness, affordances, practical knowledge, etc. are useful notions to provide an account of primitive intentionality precisely because those notions capture the idea of cognitive states as states that are normatively guided by their targets.

In (Hutto and Myin, 2017, p. 116; Hutto and Myin, 2018, p. 197; Hutto et all, 2018, p.8) $H \& M$ admit that Ur-intentionality is a normative notion so that in their interchanges with the environment basic minds are not like heat-seeking missiles. I am not sure if that is a way to recognize that it is plainly not true that correctness conditions are not needed at all

22 "all the way out to the impressions of sensibility themselves" (McDowell, 1996, p.69) 
in an account of cognition, or if it is a way to recognize that normative guidance is needed and that there is a kind of normative guidance not reducible to correctness conditions. Anyway the comparison with remote-heat-seeking missiles would be inadequate to characterize basic kinds of cognition because possibilities for actions, in the ecological psychology framework, are normally construed in terms of abilities, that is, in terms of what the organism knows how to do. Still, H\&M's would reply that anyhow the organism does not need to have fine-grained representations of their targets. Extensionally determined targets are enough. That is, an organism can be sensible to the guidance of the normative conditions that fix the intentional target, but there is no any need for the organism to represent explicitly that sensitivity. In other words, dispositions to act in some way or other according to what is afforded can be extensionally fixed by natural selection history and experienced under some phenomenal aspects although not necessarily intensionally represented (see Hutto and Myin, 2018, p.197).

Admittedly, the extensionally determined targets of primitive directionality might be experienced under some felt, phenomenal aspect. These phenomenal aspects could also be bound up with a practical responsiveness to worldly offerings, a current responsiveness that is based on organisms' previous histories of responding. The historical dimension of the norms linked to this kind of responsiveness need not be more fixed into a specific moment in a creature's evolutionary history than are Millikan's adapted and derived proper functions. The historical dimension of that practical responsiveness goes beyond a specific moment because, admitting Putnam's point, it is connected to counterfactual evaluations through a biological explanation. There are however some other critics against $H \& M$ 's teleosemiotics (the content-purged version of teleosemantics) that go beyond Putnam's argument.

Firstly, in order for the biological explanation to provide a success account of the organism's practical ability, the adequacy of that practical responsiveness to the phylogenetic historical record does not need to tell us anything about how the extensionally determined target of the organism's practical responsiveness is phenomenally experienced. We can tell a story about how certain ways of practical responsiveness to worldly offerings are etiologically selected because of its adaptive power. But that story does not need to state anything about how those worldly offerings are experienced or presented in organism's experiences. There is nothing that prevents us to tell those two stories in a convergent way: the natural selection account of a practical ability and the attribution of phenomenal character to states of that practical ability. But the possibility of developing two convergent stories is not equivalent to fulfill the requirement of provide an explanation. What an explanation should give us is a story about how a phenomenon (for instance, a natural practical ability) is constitutively or sufficiently related to another one (for instance, the phenomenal character of its states), not that two phenomena can converge.

\section{Secondly, $H \& M$ claim that:}

REC's account of basic cognition leaves room for worldly offerings to be experienced under aspects ... the things creatures engage with can look or feel as certain way. But, we hold, such phenomenally charged ways of experiencing things neither entail nor are best explained by appeal to intensional contents (See Hutto 2006; Hutto and Myin 2013, Ch. 8). That basic cognition might be intentional but not intensional is consistent with perceptual experiences having particular phenomenal characters. There are ways that the world is experienced even if experiencing is not intrinsically contentful (Hutto and Myin, 2018, p.197).

Given that, "intensionality is implied if a mental state is to represent their targets as being a certain way" (Hutto and Myin, 2018, p.191), it is difficult to see how "the things creatures engage with can look or feel as certain way" and to claim that such attributions of phenomenal contents do not entail attributions of intensional contents. The point, presumably, is that to present the world being in certain way is not tantamount to represent the world being that way. Something can look or feel in a way that is extensionally - and do no need to be intensionally- determined. In that respect, $H \& M$ rely on Releigh (2015, p.1236) to explain how something can be extensionally presented ("looks F", "looks G", "looks $\left.\mathrm{H}^{\prime \prime}\right)$ without looking as being a certain way. To complete this account, it should be possible for those extensionally presented looks to serve as evidence for cognitive states. But how can extensional looks have an epistemic impact? The divide and conquer strategy -to deny that cognition always or necessarily involves contents, accepting that basic cognition is a kind of cognition that does not require or entails normative guidance, yet admitting non-basic contentful forms of cognition that require or entail normative guidancewould be a good strategy if one would be able to tell why and how non-normatively guided forms of responsiveness to the world have a cognitive impact. Content-purged versions of teleosemantics do not do the work because they tell us how certain practical abilities to be responsive to worldly offerings are etiologically selected without any need to tell us how and why that responsiveness has some impact in the cognitive life of the individual. The ecological conception of affordances and practical responsive abilities tell us how and why that responsiveness has some impact in the cognitive life of the individual at the expense of assuming that affordances and practical responsive abilities normatively guide the individual's engagement with his surroundings. Therefore, 


\section{Philosophy International Journal}

either we avoid the normatively guided conception and then we do not seem to have enough -non casual- resources to explain how those forms of responsiveness to the world have a cognitive impact, or we introduce notions of forms of responsiveness with enough resources to explain how those forms are able to have a cognitive impact but, then we are assuming a normatively guided conception of the mind.

It will require a sophisticated battery of philosophical arguments to prove that basic minds directly experience extensions and to prove that the way things look for them as extensions can have an epistemic impact -without relying on an explanation about how that-way-things-look can be taken by the organism as that-way-things-look-. I do not know exactly which is RECers's argument to prove that something can be looked $\mathrm{F}$ without being looked as $\mathrm{F}$ and still perform an epistemic role. Anyway this argument is not to be found on the teleological account or in the ecological conception of affordances and practical responsive abilities. The possibility of the convergence of the two accounts (an account of the phenomenal character of experience and a teleological account about to what they are directed at) is not by itself an explanation. At least, if there is a way to constitutively or sufficiently relate phenomenal and (ur-)intentional contents, it is not completely clear why that explanation should jettison NCC. In fact, sometimes $H \& M$ seem to endorse a normatively guided conception of responsiveness. When they claim that "the notion of embodied responsiveness that radical enactivism promotes cannot be adequately understood in terms of simple, blind mechanisms that are incapable of any kind of novel adjustment to circumstance" (Hutto and Myin, 2018, p.197), they seem to be thinking something close to a previous mentioned idea: practical responsiveness of basic minds should be open to different (and sometimes novel) ways to be committed to worldly offerings.

I said in the first section that $H \& M$ challenge us to provide an argument to state that being presented in experience (to have an experience with phenomenal content) requires the frame of normatively guided contents (to be able to grasp contents). They claim that providing that argument requires to reduce phenomenal contents to semantic contents. But there is no need to reduce phenomenal contents to semantic contents in order to show that there is a constitutive relation between being presented in experience as an experienceelement and having the function of being able to make right or wrong turn into how worldly offerings are presented in experience. Travis's quotation can be recast for experiential cases substituting "thoughts" by "experiences", "thoughtelements" by "experience-elements", "objects" by "worldly offerings" and "makes truth turn (in part) in a certain way on how things are" by "makes being right or wrong turn in a certain way on worldly offerings". Paraphrasing: in the case of experiences about worldly offerings, the things given in experience are decomposed as elements which make the experience about those worldly offerings: for it to be that experience is for being right or wrong to turn on those worldly offerings, i.e., to take that worldly offering as right or wrong or to be committed in some way to such worldly offerings. Such experiences' elements make rightness turn in a certain way on how those offerings are experienced. No worldly offering makes -by itself- having an experience to turn onto it. ${ }^{23}$

Frege's and Wittgenstein's argument against the reduction of normative commitments to regularities is a general one. It can be applied to cases of thought but also to experiential cases to show that in order to have a direct experience of worldly offerings, it is not enough to have experiences of -normatively unframed- extensions. Thoughts and experiences have an epistemic impact and are normatively guided because what is presented in experiences and thoughts is not plainly given. Even if looks are extensionally individuated, they perform an epistemic role when they are inscribed in a normative guiding and content involving framework. In Travis' words:

seeing (where the verb is perceptual) is absolutely extensional. If Pia saw a kiewit, then she saw a green plover (a lapwing for the English among us, a northern lapwing for us continentals). Also a peewit, or pewit, or tew-wit. If that bird is the same Sid saw yesterday, then she saw the bird Sid saw yesterday. She saw the source of a certain outlawed delicacy. And so on ad lib and ad inf. This alone shows that seeing by itself does not make for proof. What Pia has proof of depends on what she has the capacity to, and was then able to, recognise. (And, to adumbrate a bit, on what was then recognisable, whether by her or by anyone) (Travis, 2017, p. 367).

To deny that the world is presented in some way implies to deny that detachability is a constitutive property of mind. In all of its interactions to its surroundings, when a basic mind has an attitude directed to something, the environment is such that way or the environment is some way and the mind fails to have a mental state that corresponds to how the environmentis, but it would not be possible to have an attitude directed to how the environment is and the environment not being that way. If the attribution of cognitive states were reduced to attributions of states that are in tandem with the world when everything goes well and are not in tandem with the world when something goes awry, there would not be any need to ascribe a mental or phenomenal character to those

23 I am using Travis formulation to frame McDowell's normative conception. I am aware that my use of Travis do not corresponds to Travis's proposal of a cognitive relation between extensional looks and recognition capacities, and that the debate between McDowell and Travis should still to be considered in order to complete an argument in favor of NCC. 


\section{Philosophy International Journal}

states. A behaviorist, a probabilistic or an account in terms of dynamic systems would be better than the postulation of a primitive intentionality explained in non-normativeguidance terms.

Now, it is plainly clear that McDowell commits himself to a conceptual characterization of how human beings are able to introduce objects in their experience and proposes to be modest and not to theorize about it. But there are some alternatives available to get some neo-Fregean insights about how to advance an enactivist and non-conceptual theory of NCC cognition. An alternative is to revise Campbell's (2002) Relational View of Experience with his characteristic appeal to conscious attention, spatial cognition and sensorymotor rules. Another one is to revise Evans's $(1982,1985)$ characterization of situated and dynamic conditions required to grasp thoughts about concrete objects. A third one is Cussins's (1993) distinction between conceptual and non-conceptual contents.

Cussins in particular provides a positive characterization of two varieties of modes of presentation -referential and mediational- relative to two different kinds of normative guidance or epistemic commitments. Two kinds of beinganswerable-to-the- world relations: truth-conditional contents that present the world as a realm of referents (paradigmatically: objects, properties, relations and possible worlds) and ecologically enactive contents that present the world as a realm of mediations (paradigmatically: affect, affordance, solicitation and glide-path structures). According to him, cognitive agents are committed to the truth through conceptual contents that present the world as referential structures (truth-makers), and semantic norms may explicitly present those structures. But cognitive agents are also committed to activities through non-conceptual contents that present the world as environmentally salient structures of guidance-in-activity (cognitive trails). There is no need to explicit those structures by any fixed set of semantic norms nor it is required for structures of guidance-in- activity to be reduced to biological phylogenetic forces of survival or adaptability. The normativity of guidance-in-activity can be as sui generis as the normativity of evolutionary adaptation and the normativity of truth.

This theoretical framework makes it possible to draw a substantial distinction between judicative or thinkable contents and experiential contents. Whereas thinkable contents are answerable to evaluations concerning their truth and present the world as a field of referents or truthmakers, experiential contents are answerable to evaluations concerning skillful performances in a given activity and present the world as a field of (guiding, correctable) mediations or activity-makers ${ }^{24}$. He proposes to characterize the notion of non-conceptual modes of presentation of mediational fields in experience as situated, environmental, action-oriented and intrinsically motivational featureplacing structures (see Murillo 2019, pp 11-19). And opposes that notion to the notion of conceptual modes of presentation of referential contents in judgments as nonsituated, truth-oriented and not necessarily motivational predicative structures.

This distinction between two ways of being-answerableto-the-world, in experience and thought, seems more promising than Gunther's or Crane's postulation of different kinds of correctness conditions (criticized in Hutto and Myin, 2017, p.101). Since, the later is still inscribed into the general idea according to which the specification of contents entails the ascription of predicative, propositional or conceptual conditions of satisfaction. It seems also more promising than Thompson's distinction between linguistic and nonlinguistic (representational and nonrepresentational) modes of presentation. Since modes of presentation even stripped from their linguistic or representational clothes -thoughtscan still present the world as a realm of referents or truthmakers.

Contradicting the previous claim according to which "we can surrender the idea that basic forms of intentionality need involve correctness or satisfaction conditions of any kind" (Hutto and Myin, 2017, pp.101-102), Hutto, et all (2018, p.10) claim the following: "we do not deny that basic emotions exhibit a kind of normativity ... there are conditions of satisfaction for such norm-guided activity but, crucially, need not be content-fully represented, as intellectualism would have it". Well, that is precisely the point: one can be Fregean without being intellectualist and argue for an enactive conception of basic cognition without avoiding a characterization of norm-guided activity.

\section{Conclusion}

In this paper I revised $R E C$ 's idea according to which a content-purged version of Millikan's teleosemantics is enough to provide an account of basic cognition. Relative to this issue, I concluded that for biological explanations to provide a success account of an organism's practical responsiveness ability, there is no need to say anything about how worldly offerings are presented in the organism's experiences. In that respect the content-purged version of teleosemantics is insufficient to explain how something can be presented in an organisms' experiences to be cognized.

24 Murillo call them action-makers, but it is clear from Cussins statements that he is talking about "simpler modes of activity" and not about actions that involve intentions. 


\section{Philosophy International Journal}

I discussed also how a neo-Fregean content-involved theory of cognition could meet H\&M challenge of providing an argument for relating ascriptions of phenomenal contents to ascriptions of correctness conditions. The argument goes through a reformulation of Frege's context principle for experiential cases. I pointed to Cussins's characterization of non-conceptual contents to show that there is no need for a neo-Fregean Normative Conception of Contentful states $(N C C)$ to commit itself to a propositional or conceptual characterization of cognition in order to show that NCC is compatible with the classical enactivist approach.

The situated and dynamic conditions that neo-Fregeans imposes on the possibility of having normatively guided cognitive states about objects approximate them to the postulation of an enactivist account of experience within a NCC neo-Fregean frame. They endorse the normatively guided conception of contentful states, but avoid the postulation of modes of presentations as intermediaries between minds and objects. Consequently their accounts do not rely on the postulation of mental representations as symbolic items that mediate that relation. They deny that purely evolutionary normativity is enough to explain how minds are cognitively engaged with the environments they are in. Even if biological explanations converge extrinsically, so to speak, with ascriptions of phenomenal contents that convergence do not explain how what is presented to a mind have a cognitive impact, i.e., how minds, even basic minds, can be answerable to the world.

\section{References}

1. Alsmith A, de Vignemont F (2012) The body represented/ Embodied representation. Review of Philosophy and Psychology.

2. Bermudez JL (2005) Thought, Reference, and Experience - Themes from the Philosophy of Gareth Evans. Oxford Scholarship Online.

3. Brandom R (1998) Making it Explicit. Harvard University Press.

4. Cappuccio M, Froese T (2014) Introduction to Making Sense of non-Sense. In: Cappuccio M, Froese T (Eds.), Enactive Cognition at the Edge of Sense-Making, Palgrave Macmillan.

5. Chemero A (2011) Radical Embodied Cognitive Science. MIT press.

6. Chemero A (2013) Radical Embodied Cognitive Science. Review of General Psychology 17(2): 145-150.
7. Clark A, Chalmers D (1998) The Extended Mind. Analysis 58(1): 7-19.

8. Clark A (2016) Surfing Uncertainty: Prediction, Action, and the Embodied Mind. Oxford University Press.

9. Crane T (2009) Is Perception a Propositional Attitude?. The Philosophical Quarterly 59(236): 452-469.

10. Campbell J (2002) Reference and Consciousness. Oxford University Press.

11. Cussins A (1990) The Connectionist Construction of Concepts. In: Boden M (Ed.), The Philosophy of Artificial Intelligence. Oxford University Press.

12. Cussins A (1992) Content, Embodiment, and Objectivity: The theory of Cognitive Trails. Mind 101(404): 651-688.

13. Cussins A (1993) Nonconceptual Content and the Elimination of Misconceived Composites. Mind and Language 8(2): 234-252.

14. Cussins A (1999) Subjectivity, Objectivity and Frames of Reference in Evan's Theory of Thought. Electronic Journal for Analytic Philosophy.

15. Cussins A (2003) Content, Conceptual Content, and Nonconceptual Content. In: Gunther Y (Ed.), Essays on Nonconceptual Content, Cambridge, Mass: MIT Press.

16. Cussins A (2012) Environmental Representations of the Body. In: Alsmith A, deVignemont F (Eds.), The body represented/Embodied representation. Review of Philosophy and Psychology 3(1).

17. Di Paolo EA, Buhrmann T, Barandiaran XE (2017) Sensorimotor Life: An Enactive Proposal. Oxford University Press.

18. Dreyfus HL (2002) Intelligence without Representation: Merleau-Ponty's critique of Mental Representation. Phenomenology and the Cognitive Sciences 1(4): 367383.

19. Dreyfus HL (2013) The Myth of the Pervasiveness of the Mental. In: Schear JK (Ed.), Mind, Reason and Being-inthe-world. Routledge.

20. Dummett M (1981) Frege: Philosophy of Language. Harvard University Press.

21. Dummett M (1987) Reply to John McDowell. In: Taylor B (Ed.), Michael Dummett: Contributions to Philosophy. Martinus Nijhoff Publishers.

22. Dummett M (1991) The Logical Basis of Metaphysics. Harvard University Press. 
23. Dummett M (1996) Origins of Analytic Philosophy. Harvard University Press.

24. Dummett M (1993) The Seas of Language. Oxford University Press.

25. Evans G (1982) The Varieties of Reference. Oxford University Press.

26. Evans G (1985) Collected Papers. Oxford University Press.

27. Fodor J (1975) The Language of Thought. Harvard University Press.

28. Fodor J (1981) Representations. Cambridge: MIT Press.

29. Fodor J (1987) Psychosemantics. Cambridge: MIT press.

30. Fodor J (1990) A Theory of Content and Other Essays. MIT Press.

31. Fodor J (1994) The Elm and the Expert: Mentalese and its Semantics. MIT press.

32. Frege G (1948) Sense and Reference. The Philosophical Review 57(3): 209-230.

33. Frege G (1956) The Thought: A Logical Inquiry. Mind 65(259): 289-311.

34. Froese T, DiPaolo EA (2011) The Enactive Approach: Theoretical Sketches from Cell to Society. Pragmatics and Cognition 19(1): 1-36.

35. Gallagher S, Zahavi D (2013) The Phenomenological Mind. Routledge.

36. Gunther Y (2003) Essays on Nonconceptual Content. MIT Press.

37. Haugeland J (1998) Truth and Rule-following. In: Haugeland J (Ed.), Having Thought: Essays in the Metaphysics of Mind. Harvard University Press.

38. Howy J (2013) The Predictive Mind. Oxford University Press.

39. Hutto DD, Myin E (2017) Evolving Enactivism: Basic Minds Meet Content. MIT Press.

40. Hutto DD, Myin E (2018) Much ado About Nothing? Why Going non-semantic is not Merely Semantics. Philosophical Explorations 21(2): 187-203.

41. Hutto DD, Robertson I, Kirchhoff MD (2018) A New Better BET: Rescuing and Revising Basic Emotion Theory. Frontiers in psychology 9: 1217.
42. Kripke SA (1982) Wittgenstein on Rules and Private Language: An Elementary Exposition. Harvard University Press.

43. Howy J (2013) The Predictive Mind. Oxford University Press.

44. Luntley M (1996) Dynamic Thoughts and Empty Minds. European Review of Philosophy 2: 77-103.

45. Mcdowell J (1996) Mind and World. Harvard University Press.

46. Mcdowell J (1998) Meaning, Knowledge and Reality. Harvard University Press.

47. Mcdowell J (2002a) Mind, Value and Reality. Harvard University Press.

48. Mcdowell J (2002b) Wittgenstein on Following a Rule. In: Mind, Value and Reality. Harvard University Press.

49. Mcdowell J (2003) Avoiding the Myth of the Given. In: Essays on Nonconceptual Content, Cambridge, Mass: MIT Press.

50. Mcdowell J (2005) Evans's Frege. In: Bermudez JL (Ed.), Thought, Reference, and Experience - Themes from the Philosophy of Gareth Evans, Clarendon Press.

51. Mcdowell J (2013) The Myth of the Mind as Detached. Routledge. In: Schear J (Ed.), Mind, Reason and Being-inthe-world. Routledge

52. Millikan RG (1984) Language, Thought and other Biological Categories. MIT press.

53. Millikan RG (1994) Biosemantics. In: Mental Representation. Cambridge: Blackwell.

54. Millikan RG (2005) Language: A Biological Model. Oxford University Press.

55. Murillo LA (2019) The Content of the Body Representations that Guide every day Action. Organon F1, pp: 29-55.

56. Neander K (2017) A Mark of the Mental: In Defense of Informational Teleosemantics. MIT Press.

57. Nöe A (2004) Action in Perception. Cambridge Mass. MIT Press.

58. Nöe A (2012) Varieties of Presence. Harvard University Press.

59. Putnam H (1992) Renewing Philosophy. Harvard University Press. 
60. Raleigh T (2015) Phenomenology without Representation. European Journal of Philosophy 23(4): 1209-1237.

61. Schear J (2013) Mind, Reason and Being-in-the-world. Routledge.

62. Schlicht $\mathrm{T}$ (2018) Does Separating Intentionality from Mental Representation Imply Radical Enactivism?. Frontiers in psychology, 9: 1497.

63. Simons P (1995) Mind and opacity. Dialectica 49(2-4): 131-146.

64. Stich S, Warfield T (1994) Mental Representation. Blackwell.
65. Sterelny K (1990) The Representational Theory of Mind. Blackwell.

66. Strawson PF (1996) Individuals: an Essay in Descriptive Metaphysics. Routledge.

67. ThompsonE(2007) Mindin Life:Biology, Phenomenology, and the Sciences of Mind. Harvard University Press.

68. Thompson E (2018) Evolving Enactivism: Basic Minds Meet Content. MIT Press.

69. Wittgenstein L (2009) Philosophical Investigations. Blackwell Publishing.

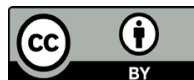

